\title{
Emergence of Dirofilaria repens (Spirurida: Onchocercidae) in dogs in Eastern Thailand
}

\author{
Wanarit Jitsamai1 (iD, Patchana Kamkong1(D), Sariya Asawakarn²,3(i) and Piyanan Taweethavonsawat ${ }^{1,2}$ (D)
}

1. Parasitology Unit, Department of Veterinary Pathology, Faculty of Veterinary Science, Chulalongkorn University, Bangkok, Thailand; 2. Biomarkers in Animal Parasitology Research Group, Chulalongkorn University, Bangkok, Thailand;

3. Biochemistry Unit, Department of Veterinary Physiology, Faculty of Veterinary Science, Chulalongkorn University, Bangkok, 10330, Thailand.

Corresponding author: Piyanan Taweethavonsawat, e-mail: piyanan.t@chula.ac.th

Co-authors: WJ: Wanarit.j@gmail.com,PK: mint.pat@gmail.com, SA: sariya.a@chula.ac.th Received: 02-06-2021, Accepted: 22-09-2021, Published online: 06-11-2021

doi: www.doi.org/10.14202/vetworld.2021.2851-2854 How to cite this article: Jitsamai W, Kamkong P, Asawakarn S, Taweethavonsawat P (2021) Emergence of Dirofilaria repens (Spirurida: Onchocercidae) in dogs in eastern Thailand, Veterinary World, 14(11): 2851-2854.

\begin{abstract}
Background and Aim: Dirofilaria repens is a zoonotic vector-borne parasite of dogs and cats. It is not commonly found in every part of Thailand, except the southern part. This study was conducted to investigate the prevalence of this parasite in Eastern Thailand in 2019.

Materials and Methods: A total of 8003 blood samples were collected from private veterinary clinics and animal hospitals in Eastern Thailand. Blood parasites were examined using buffy coat thin blood smears with Wright-Giemsa staining. $D$. repens was morphologically identified and confirmed using the acid phosphatase activity technique.
\end{abstract}

Results: The first case of $D$. repens was found in March 2019. The prevalence of $D$. repens from January to December 2019 was $0.44 \%$ (35/8003) (95\% confidence interval 0.30-0.61).

Conclusion: The prevalence data of D. repens in Eastern Thailand indicate that this parasitic infection should be considered as a zoonotic vector-borne disease. A strategic plan to control zoonotic transmission alongside a preventive program should be emphasized and encouraged among pet owners and veterinarians.

Keywords: Dirofilaria repens, dog, emerging, prevalence, Thailand, zoonosis.

\section{Introduction}

Several filarial nematodes are found worldwide, especially in tropical countries such as Thailand that have a suitable climate for the mosquito vector. In Thailand, filariasis is caused by Dirofilaria immitis, Brugia malayi, Brugia pahangi, and Acanthocheilonema (Dipetalonema) reconditum [1-4]. Dirofilaria repens is a nonpathogenic canine filarial nematode that is also found in cats and humans [5]. The epidemiology of $D$. repens was first investigated in Southern Europe and expanded to Northern Europe [6-8]. In recent years, some studies have suggested that $D$. repens in Asia has higher diversity than that in European countries, including Candidatus D. hongkongensis from Hong Kong and D. repens "Thailand II" found in Narathiwat Province, Thailand $[5,9,10]$. D. repens has also been detected in other parts of Thailand, including Bangkok, but the prevalence was very low [11]. Humans are considered as an accidental host for dirofilariasis. Humans infected with $D$. repens commonly manifest two

Copyright: Jitsamai, et al. Open Access. This article is distributed under the terms of the Creative Commons Attribution 4.0 International License (http://creativecommons.org/licenses/ by/4.0/), which permits unrestricted use, distribution, and reproduction in any medium, provided you give appropriate credit to the original author(s) and the source, provide a link to the Creative Commons license, and indicate if changes were made. The Creative Commons Public Domain Dedication waiver (http:// creativecommons.org/publicdomain/zero/1.0/) applies to the data made available in this article, unless otherwise stated. clinical forms of filariasis, namely, subcutaneous and ocular [7]. Nodules in subcutaneous tissues are generally approximately $1 \mathrm{~cm}$ in size and sometimes may present clinical signs such as cutaneous larval migration, including irritation and itching [12]. The ocular form is primarily found in the subconjunctival region. In cases of chronic infection that is not diagnosed in a timely manner, the parasites can migrate into the peri-, intra-, and retro-ocular spaces, resulting in complications such as damaged vision, floaters, glaucoma, retinal detachment, vitreous opacity, loss of visual acuity, and blindness [13]. In Thailand, ocular dirofilariasis due to $D$. repens infection was reported to cause a cystic mass in the eyelid of a woman living in Phangnga province [14]. Recently, the first case of subconjunctival dirofilariasis was reported in a woman in Bangkok, Thailand [15].

The mode of transmission of $D$. repens is similar to that of $D$. immitis. Mosquitoes belonging to the genera Anopheles, Aedes, and Culex are potential vectors for Dirofilaria spp. $[16,17]$. D. immitis infection in dogs causes cardiopulmonary diseases, but $D$. repens infection causes milder disease in subcutaneous tissues [18]. Dirofilariasis caused by D. repens is considered as a nonpathogenic disease. However, recent research has suggested that subcutaneous dirofilariasis is associated with dermatological symptoms together with concomitant pruritus, neoplastic processes, inflammation, and blindness in dogs and humans [19]. 
It was observed that the blood parameters in dogs were altered during infection, with a reduction in the number of white blood cells, red blood cells, and platelets and an increase in alkaline phosphatase and creatinine activities [19].

In Thailand, the majority of studies have focused on the southern part of Thailand, which is an endemic area of filariasis as the climatic conditions are suitable for the vector. However, there are limited epidemiological data concerning canine subcutaneous dirofilariasis in eastern Thailand, which has a similar climate. Therefore, this study was conducted to explore the prevalence of filariasis in Eastern Thailand during 2019.

\section{Materials and Methods}

\section{Ethical approval}

The research protocol was approved by Chulalongkorn University Animal Care and Use Committee (approval no. 2031065).

\section{Study period and location}

This retrospective study was conducted from January to December 2019. Records of D. repens were obtained from the central veterinary laboratory, Rayong branch, which collected canine blood samples from private veterinary clinics and animal hospitals in seven provinces in Eastern Thailand, including Chonburi, Rayong, Chanthaburi, Trat, Chachoengsao, Prachin Buri, and Sa Kaeo (excluding Pattaya city, a municipal area).

\section{Blood collection and parasite identification}

A total of 8003 EDTA-blood samples were collected from owned dogs and submitted to the Central Veterinary Laboratory, Rayong branch. Buffy coat thin blood smears were prepared and stained with Wright-Giemsa. The stained smears were examined for the presence of microfilaria under a light microscope. Unsheathed microfilaria with two nuclei at the cephalic space was evaluated for their acid phosphatase activity to identify D. repens [20].

\section{Statistical analysis}

The prevalence of $D$. repens is presented using descriptive statistics and 95\% confidence intervals (CIs).

\section{Results and Discussion}

From January to December 2019, a total of 8003 blood samples were examined, of which $0.44 \%$ (35/8003) $(95 \%$ CI $0.30-0.61)$ were $D$. repens-positive. The microfilaria of $D$. repens was identified using the buffy coat smear with Wright-Giemsa staining and the acid phosphatase activity test (Figure-1a and b, respectively). A map of the private veterinary clinics and animal hospitals in Rayong and Chanthaburi Provinces is depicted in Figure-2. Coinfection with B. pahangi, Hepatozoon canis, Babesia spp., Ehrlichia canis, and D. immitis was observed (Table-1). The prevalence in each month is presented in Table-2;

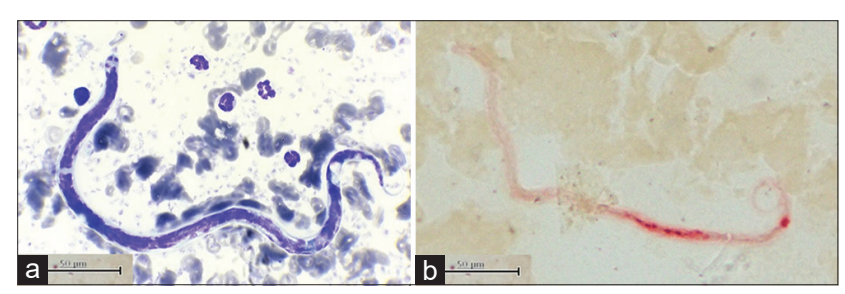

Figure-1: Microfilaria of Dirofilaria repens in (a) Giemsastained buffy coat smear and (b) acid phosphatase activity test.

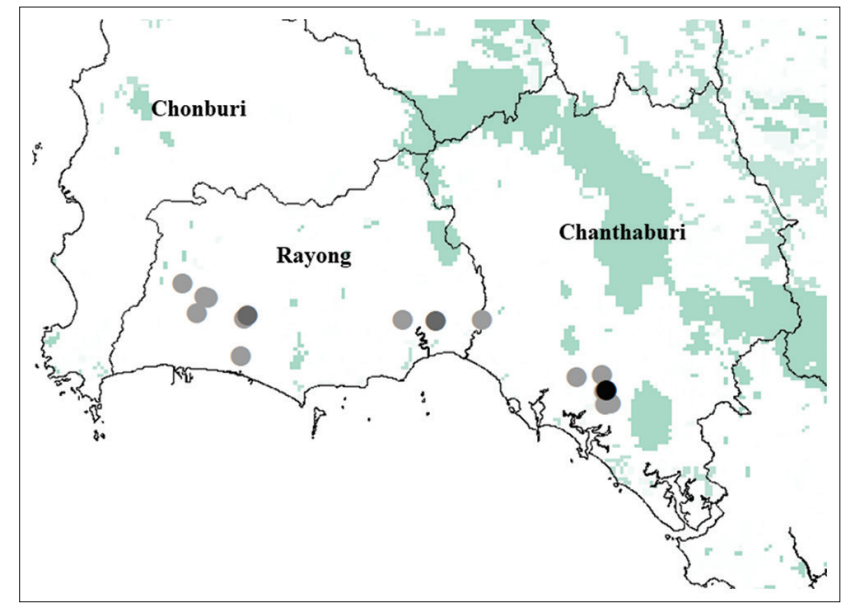

Figure-2: Locations of private veterinary clinics and animal hospitals and prevalence of filariasis demonstrated by dots (greyscale $<2$ cases, dark grey $2-4$ cases, and black $>4$ cases) during January to December 2019. Source: The map was constructed using base map from GADM, version 1.0 for administrative areas and GLC2000 for land cover. (https://www.diva-gis.org/gdata)

the highest prevalence of $D$. repens was observed in August, at 1.2\% (95\% CI 0.55-2.27).

D. repens was first reported in the eastern part of Thailand in 2019. A large number of samples were collected from infected dogs, which may have influenced the prevalence recorded herein. However, we were not able to performed a gold standard test for microfilarial count such as the Knott or filtration test. This represents a limitation of this study and decreases the accuracy of our results in terms of sensitivity and specificity [21]. Furthermore, the samples were obtained from a clinical laboratory, and hence we do not have any details regarding the sex and breed of the infected dogs.

In the present study, we detected $35 \mathrm{D}$. repens cases among the 8003 examined samples in 2019, and three dogs showed clinical signs such as lethargy, loss of appetite, and epistaxis. It has been hypothesized that infected dogs do not present any clinical signs. Canine subcutaneous dirofilariasis is considered to be asymptomatic. However, some cases presented subcutaneous nodules. Circulating microfilaria causes cutaneous lesions, resulting in pruritus, alopecia, erythema, and diffused dermatitis [22]. In addition to the subcutaneous space, adult $D$. repens has been reported in several sites, including the bulbar subconjunctiva, retroperitoneal space of the pelvic cavity, and mesentery in the abdomen [23]. Although coinfection 
Table-1: Coinfection of $D$. repens with other vector-borne pathogens.

\begin{tabular}{lcc}
\hline Coinfection & $\begin{array}{c}\text { Prevalence } \\
\text { (n) }\end{array}$ & 95\% CI \\
\hline Single infection of D. repens & $0.32(26)$ & $0.21-0.48$ \\
D. repens with D. immitis & $0.01(1)$ & $0.00-0.07$ \\
D. repens with B. pahangi & $0.05(4)$ & $0.01-0.13$ \\
D. repens with Babesia spp. & $0.01(1)$ & $0.00-0.07$ \\
D. repens with B. pahangi & $0.02(2)$ & $0.00-0.09$ \\
and $H$. canis & & \\
$\begin{array}{l}\text { D. repens with B. pahangi, } \\
\text { and E. canis }\end{array}$ & $0.01(1)$ & $0.00-0.07$ \\
\end{tabular}

D. repens=Dirofilaria repens, $D$. immitis=Dirofilaria immitis, $B$. pahangi=Brugia pahangi,

H. canis=Hepatozoon canis, E. canis=Ehrlichia canis, $\mathrm{CI}=$ Confidence interval

Table-2: Prevalence of Dirofilaria repens in each month from January to December 2019.

\begin{tabular}{lccc}
\hline Month & $\begin{array}{c}\text { Number } \\
\text { of dogs }\end{array}$ & Prevalence (\%) & $\mathbf{9 5 \%}$ CI \\
\hline January & 600 & 0.00 & $0.00-0.00$ \\
February & 590 & 0.00 & $0.00-0.00$ \\
March & 775 & 0.13 & $0.00-0.72$ \\
April & 630 & 0.95 & $0.35-2.06$ \\
May & 700 & 0 & $0.00-0.00$ \\
June & 650 & 0.15 & $0.00-0.85$ \\
July & 735 & 0.54 & $0.15-1.39$ \\
August & 750 & 1.20 & $0.55-2.27$ \\
September & 654 & 0.46 & $0.09-1.33$ \\
October & 665 & 0.30 & $0.04-1.08$ \\
November & 635 & 0.94 & $0.35-2.04$ \\
December & 619 & 0.48 & $0.10-1.41$ \\
\hline
\end{tabular}

$\mathrm{CI}=$ Confidence interval

with $B$. pahangi was the most common in this study, the clinical presentations have not been previously reported. Natural coinfection of $D$. repens and $D$. immitis results in cachexia, with systemic muscle wasting. In a previous study, $D$. immitis and $D$. repens were found ectopic from cardiopulmonary and subcutaneous sites through histopathological investigation of the liver, kidney, and spleen, resulting in lymphocyte infiltration, fibrosis, and mineralization [23].

Human dirofilariasis due to $D$. repens infection commonly causes subcutaneous nodules. However, some cases have been reported in ectopic sites, including the lungs, scrotum, penis, spermatic cord, epididymis, and female mammary glands [24]. In ocular dirofilariasis, parasites were detected in periocular tissues [25]. To control zoonotic transmission, pet owners and veterinarians must be encouraged to follow a preventive program. Besides the aforementioned potential vector, Armigeres spp. is a potential vector in some regions [26,27]. The tropical fruit and rubber orchards that are abundant in the eastern agricultural area of Thailand serve as suitable habitats for Armigeres spp. as in the southern part, which is also rich in rubber orchards. The clinical signs of $D$. repens infection in humans and animals are mild and might be ignored [23], especially in orchard laborers and orchard guard dogs, for socioeconomic reasons.

\section{Conclusion}

D. repens was first reported in eastern Thailand in March 2019 and was found to be most prevalent in August. Armigeres spp. is considered as a potential vector as there are suitable habitats in the fruit and rubber orchards that are commonly found in Eastern Thailand. Pet owners and veterinarians should be encouraged to follow a preventive and treatment program to manage zoonotic transmission.

\section{Authors' Contributions}

WJ and PT: Designed the study. WJ, PK, SA, and PT: Contributed to the analysis and interpretation of data. WJ and PT: Wrote the manuscript. PK and SA: Assisted in writing and revision of the manuscript. All authors have read and approved the final manuscript.

\section{Acknowledgments}

This work was supported by the Special Task Force for Activating Research, Chulalongkorn University, Thailand (Grant no. STF 6401531001-1). The authors would like to thank Vet Central Lab staff for supporting the laboratory work.

\section{Competing Interests}

The authors declare that they have no competing interests.

\section{Publisher's Note}

Veterinary World remains neutral with regard to jurisdictional claims in published map and institutional affiliation.

\section{References}

1. Satjawongvanit, H., Phumee, A., Tiawsirisup, S., Sungpradit, S., Brownell, N., Siriyasatien, P. and Preativatanyou, K. (2019) Molecular analysis of canine filaria and its wolbachia endosymbionts in domestic dogs collected from two animal university hospitals in Bangkok Metropolitan region, Thailand. Pathogens, 8(3): 114.

2. Kanjanopas, K., Choochote, W., Jitpakdi, A., Suvannadabba, S., Loymak, S., Chungpivat, S. and Nithiuthai, S. (2001) Brugia malayi in a naturally infected cat from Narathiwat Province, Southern Thailand. Southeast Asian J. Trop. Med. Public Health, 32(3): 585-587.

3. Kamyingkird,K.,Junsiri,W.,Chimnoi,W.,Kengradomkij,C., Saengow, S., Sangchuto, K., Kajeerum, W., Pangjai, D., Nimsuphan, B. and Inpankeaw, T. (2017) Prevalence and risk factors associated with Dirofilaria immitis infection in dogs and cats in Songkhla and Satun Provinces, Thailand. Agric. Nat. Resour., 51(4): 299-302.

4. Wongkamchai, S., Nochote, H., Foongladda, S., Dekumyoy, P., Thammapalo, S., Boitano, J.J. and Choochote, W. (2014) A high resolution melting real-time PCR for mapping of filaria infection in domestic cats living in brugian filariosis-endemic areas. Vet. Parasitol., 201(1-2): 120-127.

5. Yilmaz, E., Fritzenwanker, M., Pantchev, N., Lendner, M., Wongkamchai, S., Otranto, D., Kroidl, I., Dennebaum, M., Le, T.H. and Anh Le, T. (2016) The mitochondrial genomes of the zoonotic canine filarial parasites Dirofilaria (Nochtiella) repens and Candidatus Dirofilaria (Nochtiella) hongkongensis provide evidence for presence of cryptic species. PLoS Negl. Trop. Dis., 10(10): e0005028.

6. Deksne, G., Jokelainen, P., Oborina, V., Lassen, B., 
Akota, I., Kutanovaite, O., Zaleckas, L., Cirule, D., Tupits, A. and Pimanovs, V. (2020) The zoonotic parasite Dirofilaria repens emerged in the baltic countries Estonia, Latvia, and Lithuania in 2008-2012 and became established and endemic in a Decade. Vector Borne Zoonotic Dis., 21(1): 1-5.

7. Pupic-Bakrac, A., Pupic-Bakrac, J., Jurkovic, D., Capar, M., Lazaric Stefanovic, L., Antunovic Celovic, I., Kucinar, J., Polkinghorne, A. and Beck, R. (2020) The trends of human dirofilariasis in Croatia: Yesterday-today-tomorrow. One Health, 10(2020):100153.

8. Otranto, D., Dantas-Torres, F., Brianti, E., Traversa, D., Petric, D., Genchi, C. and Capelli, G. (2013) Vector-borne helminths of dogs and humans in Europe. Parasit. Vectors, 6(38): 16 .

9. Yilmaz, E., Wongkamchai, S., Ramunke, S., Koutsovoulos, G.D., Blaxter, M.L., Poppert, S., Schaper, R., von Samson-Himmelstjerna, G. and Krucken, J. (2019) High genetic diversity in the Dirofilaria repens species complex revealed by mitochondrial genomes of feline microfilaria samples from Narathiwat, Thailand. Transbound. Emerg. Dis., 66(11): 389-399.

10. To, K.K., Wong, S.S., Poon, R.W., Trendell-Smith, N.J., Ngan, A.H., Lam, J.W., Tang, T.H., AhChong, A.K., Kan, J.C. and Chan, K.H. (2012) A novel Dirofilaria species causing human and canine infections in Hong Kong. J. Clin. Microbiol., 50(11): 3534-3541.

11. Taweethavonsawat, P. and Chungpivat, S. (2020) Case report: Subcutaneous canine dirofilariasis (Dirofilaria repens) in Bangkok, Thailand. Thai. J. Vet. Med., 50(1): 67-68.

12. Capelli, G., Genchi, C., Baneth, G., Bourdeau, P., Brianti, E., Cardoso, L., Danesi, P., Fuehrer, H.P., Giannelli, A. and Ionica, A.M. (2018) Recent advances on Dirofilaria repens in dogs and humans in Europe. Parasit. Vectors, 11(1): 663.

13. Ilyasov, B., Kartashev, V., Bastrikov, N., Morchon, R., Gonzalez-Miguel, J. and Simon, F. (2013) Delayed diagnosis of dirofilariasis and complex ocular surgery, Russia. Emerg. Infect. Dis., 19(2): 326-328.

14. Jariya, P. and Sucharit, S. (1983) Dirofilaria repens from the eyelid of a woman in Thailand. Am. J. Trop. Med. Hyg., 32(6): 1456-1457.

15. Sukudom, P., Phumee, A. and Siriyasatien, P. (2018) First report on subconjunctival dirofilariasis in Thailand caused by a Dirofilaria spp. closely related to $D$. hongkongensis. Acad. J. Sci. Res., 6(3): 114-116.

16. Labarthe, N., Serrão, M.L., Melo, Y.F., Oliveira, S.J.D. and Lourenço-de-Oliveira, R. (1998) Potential vectors of Dirofilaria immitis (Leidy, 1856) in Itacoatiara, Oceanic region of Niterói municipality, State of Rio de Janeiro,
Brazil. Memórias Inst. Oswaldo Cruz., 93(4): 425-432.

17. Ledesma, N. and Harrington, L. (2011) Mosquito vectors of dog heartworm in the United States: Vector status and factors influencing transmission efficiency. Top. Companion Anim. Med., 26(4): 178-185.

18. Demirci, B., Bedir, H., Tasci, G.T. and Vatansever, Z. (2021) Potential mosquito vectors of Dirofilaria immitis and Dirofilaira repens (Spirurida: Onchocercidae) in Aras Valley, Turkey. J. Med. Entomol.,58(2): 499-501.

19. Wysmolek, M.E., Dobrzynski, A., Dlugosz, E., Czopowicz, M., Wisniewski, M., Jurka, P. and Klockiewicz, M. (2020) Hematological and biochemical changes in dogs naturally infected with Dirofilaria repens. Front. Vet. Sci., 7:590.

20. Chungpivat, S. and Taweethavonsawat, P. (2008) The differentiation of microfilariae in dogs and cats using Giemsa's staining and the detection of acid phosphatase activity. J. Thai. Vet. Pract., 20(1): 47-55.

21. Laidoudi, Y., Marie, J.L., Tahir, D., Watier-Grillot, S., Mediannikov, O. and Davoust, B. (2020) Detection of canine vector-borne filariasis and their wolbachia endosymbionts in French Guiana. Microorganisms, 8(5): 770.

22. Tarello, W. (2002) Cutaneous lesions in dogs with Dirofilaria (Nochtiella) repens infestation and concurrent tick-borne transmitted diseases. Vet. Dermatol., 13(5): 267-274.

23. Mircean, M., Ionica, A.M., Mircean, V., Gyorke, A., Codea, A.R., Tabaran, F.A., Taulescu, M. and Dumitrache, M.O. (2017) Clinical and pathological effects of Dirofilaria repens and Dirofilaria immitis in a dog with a natural co-infection. Parasitol. Int., 66(3): 331-334.

24. Sabunas, V., Radzijevskaja, J., Sakalauskas, P., Petkevicius, S., Karveliene, B., Ziliukiene, J., Lipatova, I. and Paulauskas, A. (2019) Dirofilaria repens in dogs and humans in Lithuania. Parasit. Vectors, 12(1): 177.

25. Pampiglione, S. and Rivasi, F. (2000) Human dirofilariasis due to Dirofilaria (Nochtiella) repens: An update of world literature from 1995 to 2000. Parassitologia, 42(3-4): 231-254.

26. Lee, S.E., Kim, H.C., Chong, S.T., Klein, T.A. and Lee, W.J. (2007) Molecular survey of Dirofilaria immitis and Dirofilaria repens by direct PCR for wild-caught mosquitoes in the Republic of Korea. Vet. Parasitol., 148(2): 149-155.

27. Dissanaike, A.S., Abeyewickreme, W., Wijesundera, M.D., Weerasooriya, M.V. and Ismail, M.M. (1997) Human dirofilariasis caused by Dirofilaria (Nochtiella) repens in Sri Lanka. Parassitologia, 39(4): 375-382. 